Extended Abstract

\title{
In Silico Analysis of the Formation of Bioactive Peptides from Silver Carp (Hypophthalmichthys molitrix) Collagen ${ }^{+}$
}

\author{
Grigore-Mihăiță Stan, Diana Constantinescu-Aruxandei * and Florin Oancea * \\ National Institute for Research \& Development in Chemistry and Petrochemistry -ICECHIM, \\ 060021 Bucharest, Romania; grigore-mihaita.stan@icechim.ro \\ * Correspondence: diana.constantinescu@icechim.ro (D.C.-A.); florin.oancea@icechim.ro (F.O.) \\ + Presented at the 16th International Symposium "Priorities of Chemistry for a Sustainable Development" \\ PRIOCHEM, Bucharest, Romania, 28-30 October 2020.
}

Published: 10 November 2020

Keywords: in silico; bioactive peptides; silver carp collagen; antihypertensive; antioxidative

Due to its unique properties, the study of collagen represents a new trend in medical, pharmaceutical, and food sciences [1]. Recently, marine organisms have been considered as potential sources of collagen, as they are not classified as potential spreaders of communicable diseases [2]. This study explored the potential of silver carp collagen protein as a precursor of bioactive peptides using an in silico approach.

A series of in silico approaches (using the BIOPEP, PeptideRanker, peptide calculator [PepCalc], and toxin prediction [ToxinPred] databases) were employed to evaluate collagen from silver carp as a potential source of bioactive peptides [3,4]. Furthermore, a number of physicochemical properties and sensory and toxicity characteristics of the most bioactive peptides with antihypertensive and antioxidant activities were predicted (Figure 1).

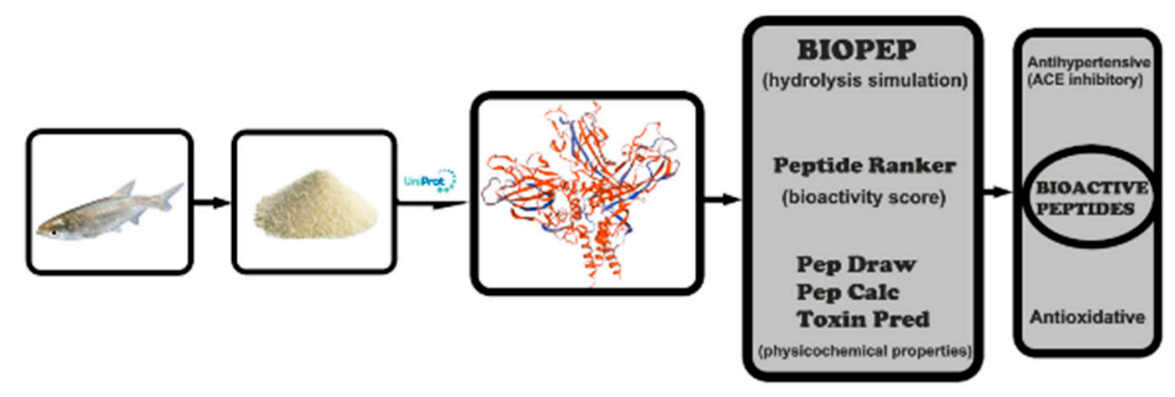

Figure 1. representation of the identification of bioactive peptides from silver carp.

Analysis of the profile of the biological activity of silver carp collagen showed possible peptides with antihypertensive and antioxidant activities. Based on the in silico hydrolysis simulation of collagen, pepsin and papain proteases can cleave the collagen protein effectively compared to subtilisin to release ACE-inhibitory peptides. The antioxidant activity was higher for subtilisin-cleaved peptides. PeptideRanker identified the peptides with the best bioactivity scores from the three enzymes analyzed. Several peptides showed good solubility in water, and all the peptides analyzed were classified as non-toxic.

Overall, this study highlights that the silver carp collagen could be a potential source of bioactive peptides with antihypertensive and antioxidant effects, and the in silico approach is a 
quick and cost-effective method for analyzing these predicted structures with health-promoting effects.

Acknowledgments: The work on this paper was supported by the Government of Romania, Ministry of Education and Research, Project 3PTE-COL-STIM financed by UEFISCDI, and Project PFE 31/2018.

\section{References}

1. Pal, G.K.; Suresh, P. Physico-chemical characteristics and fibril-forming capacity of carp swim bladder collagens and exploration of their potential bioactive peptides by in silico approaches. Int. J. Biol. Macromol. 2017, 101, 304-313, doi:10.1016/j.ijbiomac.2017.03.061.

2. Pati, F.; Adhikari, B.; Dhara, S. Isolation and characterization of fish scale collagen of higher thermal stability. Bioresour. Technol. 2010, 101, 3737-3742, doi:10.1016/j.biortech.2009.12.133.

3. Minkiewicz, P.; Dziuba, J.; Iwaniak, A.; Dziuba, M.; Darewicz, M. BIOPEP Database and Other Programs for Processing Bioactive Peptide Sequences. J. AOAC Int. 2008, 91, 965-980, doi:10.1093/jaoac/91.4.965.

4. Lear, S.; Cobb, S.L. Pep-Calc.com: a set of web utilities for the calculation of peptide and peptoid properties and automatic mass spectral peak assignment. J. Comput. Mol. Des. 2016, 30, 271-277, doi:10.1007/s10822-016-9902-7.

Publisher's Note: MDPI stays neutral with regard to jurisdictional claims in published maps and institutional affiliations.

(C) 2020 by the authors. Licensee MDPI, Basel, Switzerland. This article is an open access article distributed under the terms and conditions of the Creative Commons Attribution (CC BY) license (http://creativecommons.org/licenses/by/4.0/). 